\title{
Plasma 25-hydroxyvitamin D and rickets in infants of extremely low birthweight
}

\author{
N MCINTOSH, A LIVESEY, AND O G BROOKE \\ Department of Child Health, St George's Hospital Medical School, London
}

SUMMARY Rickets is now a well-known entity in infants of very low birthweight. In a 1-year period (1981) 8 of 15 neonatal survivors whose birthweight was less than $1000 \mathrm{~g}$ (extremely low birthweight) developed rickets despite high supplementation with ergo-calciferol, 2000 units a day. At the time of radiological diagnosis their postnatal age was 8 (range 5-14) weeks, and they all had normal or high plasma concentrations of 25-hydroxyvitamin D (mean $80 \mathrm{nmol} / 1$, range $40-160 \mathrm{nmol} / \mathrm{l}$ ). Although 4 infants received alfacalcidol which healed the rickets, in 4 infants the rickets healed spontaneously without change in treatment. The results suggest that inadequate vitamin D supplementation is not the cause of rickets in such infants.

The incidence of rickets in infants of low birthweight may be as high as $32 \%{ }^{12}$ Spontaneous rib fractures ${ }^{3}$ and late onset respiratory distress ${ }^{4}$ may lead to significant morbidity in this fragile group of babies. The aetiology of the condition is unclear. Although calcium $^{5}$ and phosphorus substrate deficiency ${ }^{6}$ have both been postulated, many people consider that inadequate vitamin $\mathrm{D}$ intake ${ }^{7}$ or metabolism is more likely to be the cause. Hillman and Haddad ${ }^{8}$ found inadequate 25 -hydroxylation of vitamin $\mathbf{D}$ in the liver of the preterm baby but Wolf et al. ${ }^{9}$ found that 25-hydroxylation was possible after 32-34 weeks' gestation. Seino et al..$^{10}$ postulated a problem of $1-\alpha$ hydroxylation in the kidney and Glasgow and Reid $^{11}$ were able to heal the rickets with alfacalcidol. The aim of our study was to determine the incidence of rickets in babies less than $1000 \mathrm{~g}$ nursed in our unit and to establish whether insufficient vitamin $\mathrm{D}$ intake was the cause.

\section{Patients and methods}

During 1981, 29 babies weighing less than $1000 \mathrm{~g}$ at birth were admitted to the neonatal unit at $\mathrm{St}$ George's Hospital. Two infants, born on site, had lethal malformations and were not offered intensive care. Of the 27 remaining infants $15(56 \%)$ survived for at least 28 days, only 1 of these subsequently dying after surgery for intussusception at age 9 weeks.

Eight $(53 \%)$ cases of rickets occurred in the 15 neonatal survivors. The median weight was 840 (range 700-990) $\mathrm{g}$ and median gestation 27.5 (range 25-28) weeks. All infants were appropriate weight for gestation, and the racial origin was similar to general admissions to the neonatal unit ( 5 white, 1 African, 1 Indian, 1 West Indian). The diagnosis of rickets was established radiologically by an independent radiologist at a mean age of 8 (range 5-14) postnatal weeks on the basis of cupping and fraying of the epiphyses with splaying of the ends of the shaft of the radius.

All infants developing rickets had received 2000 units of vitamin $D$ daily from age 7 days (1600 units of ergo-calciferol and 400 units in a multivitamin preparation). All infants were initially fed on expressed breast milk, either fresh from the mother or, if from a donor, generally pasteurised. Five infants received only expressed breast milk. One 3-week-old infant was changed to Prematalac because of hypoproteinaemic oedema and 2 others were changed to Prosobee at age 8 weeks (rickets was evident before this change was made). The maximum volume of milk was $220 \mathrm{ml} / \mathrm{kg}$ a day. No supplementary calcium or phosphorus was given.

The clinical problems of these babies are shown in Table 1. Levels of plasma calcium, phosphorus, and alkaline phosphatase were measured regularly, about fortnightly, and wrist $x$-ray films were performed if the alkaline phosphatase levels were greatly raised.

Plasma calcium, ${ }^{12}$ phosphorus, ${ }^{13}$ and alkaline phosphatase $^{14}$ were measured using our standard laboratory autoanalyser methods (Technicon AA II). When rickets was diagnosed, plasma 25-hydroxyvitamin $\mathrm{D}$ was measured by competive proteinbinding assay. ${ }^{15}$

At the time of diagnosis 4 infants were moderately 
Table 1 Rickets in 8 infants of extremely low birthweight

\begin{tabular}{ll}
\hline Clinical conditons & Number of infants \\
\hline Respiratory distress syndrome & 5 \\
Patent ductus arteriosus & 5 \\
Ventilation (more than 7 days) & 5 \\
Intravenous feeding (more than 7 days) & 5 \\
Regular treatment with frusemide & 4 \\
Regular treatment with bicarbonate & 3 \\
Chest infection & 3 \\
Bronchopulmonary dysplasia & 3 \\
Subglottic stenosis & 1 \\
Jaundice of intravenous feeding & 1 \\
Gut problems (intussusception) & 1 \\
\hline
\end{tabular}

Table 2 Biochemical findings at diagnosis of rickets in 8 infants of extremely low birthweight

\begin{tabular}{lcc}
\hline & Mean & Range \\
\hline Calcium (mmol/l) & $2 \cdot 32$ & $2 \cdot 05-2 \cdot 57$ \\
Phosphate (mmol/1) & $1 \cdot 13$ & $0 \cdot 4-1 \cdot 7$ \\
Alkaline phosphatase (U/1) & 919 & $552-1215$ \\
25-hydroxyvitamin D (nmol/l) & 80 & $40-160$ \\
\hline
\end{tabular}

Conversion: SI to traditional units-calcium: $1 \mathrm{mmol} / 1 \approx 4 \mathrm{mg} / 100 \mathrm{ml}$; phosphate: $1 \mathrm{mmol} / \mathrm{l} \approx 3.09 \mathrm{mg} / 100 \mathrm{ml}$; 25 hydroxyvitamin $\mathrm{D}$ : $1 \mathrm{nmol} / 1 \approx 0.04 \mathrm{ng} / \mathrm{ml}$.

ill with respiratory problems and although these were not considered to be primarily of rachitic origin it was thought prudent to change their vitamin $\mathrm{D}$ therapy to $0 \cdot 33 \mu \mathrm{g}$ alfacalcidol daily. The remaining 4 infants were observed without change in vitamin $\mathbf{D}$ therapy.

\section{Results}

The plasma concentrations of calcium, phosphorus, and 25-hydroxyvitamin $\mathrm{D}$, and the activity of plasma alkaline phosphatase are shown in Table 2. Although the mean plasma calcium and phosphorus levels were in the normal range, 2 patients were hypocalcaemic and 1 hypophosphataemic compared with our normal paediatric range. The alkaline phosphatase activity ranged between 552 and $1215 \mathrm{U} / \mathrm{l}$. Only one patient had isoenzyme fractionation which confirmed a predominantly bone pattern. The plasma 25-hydroxyvitamin D levels were either well within the normal range for our laboratory (20-150 $\mathrm{nmol} / \mathrm{l}$ ) or high. The use of 1 alfacalcidol was associated with radiological improvement over about 3 weeks' treatment, but the infants who had no change in treatment also showed radiological improvement.

\section{Discussion}

The incidence of rickets in this group of extremely low birthweight infants is higher than has so far been reported. ${ }^{12}$ These infants generally had had compli- cated problems but despite very high-dose vitamin D supplementation developed rickets. We know of no other reports of the routine use of such high doses of ergo-calciferol. The implication that these infants were not vitamin D-deficient is confirmed by the high or high normal plasma levels of 25-hydroxyvitamin D. It has previously been suggested that the levels of plasma 25-hydroxyvitamin $\mathrm{D}$ are reduced in the preterm newborn. ${ }^{10}$ Hillman and Haddad $^{8}$ found that there was no increase with supplements until 36 weeks' gestation but Wolf et al. ${ }^{9}$ reported an increase at 32-34 weeks. In cases of rickets the plasma 25-hydroxyvitamin $D$ levels have usually been reported as low $^{7810}$ but these authors have always used very much lower vitamin $\mathbf{D}$ supplements than in our study. It is possible that $1-\alpha$ hydroxylation in the kidney is inadequate. Rowe et al., ${ }^{6}$ Steichen et al., ${ }^{16}$ and Chesney et al. ${ }^{17}$ have all shown high 1,25 hydroxy D levels which suggests that renal hydroxylation is active in this condition. Alfacalcidol did appear to lead to healing of rickets in 3 out of 4 cases, but in 4 others spontaneous healing occurred without change in vitamin $\mathbf{D}$ therapy suggesting that alfacalcidol treatment may not have been the cause of the healing. We have no evidence to favour or refute the hypothesis of Chudley et al. ${ }^{18}$ that there is peripheral insensitivity to the action of 1,25 dihydroxyvitamin $\mathrm{D}$. There remains the possibility of substrate deficiency of either calcium or phosphate. It is highly likely that our high risk group were substrate deficient as the content of calcium and phosphorus in breast milk is very low. ${ }^{6}$ Fat malabsorption is also likely in these infants of extremely low birthweight and this will tend to exaggerate calcium malabsorption. To add to this substrate deficit, 3 of our babies were for quite a long period on the loop diuretic frusemide which is known to have a calciuric action. This has been considered of possible importance by Chudley $e t$ al. as has associated sodium deficiency. ${ }^{18}$ Two of our infants at diagnosis had low plasma calcium levels and one a low plasma phosphorus. The spontaneous healing in the 4 babies without change in vitamin $D$ therapy could be accounted for by the increase in oral intake as the general condition of the infants improved or by the cessation of the need for frusemide treatment. All our levels of alkaline phosphatase were raised but were much lower than those recently given by Kovar et al ${ }^{19}$ This is almost certainly accounted for by the more routine method of measurement by our laboratory and we feel it is worth stressing that Kovar et al. ${ }^{19}$ used highly sensitive rate reaction methods for measurement of alkaline phosphatase which are not performed in most routine laboratories, and thus if one waits for such high levels, rickets may well be established. 
We thank Dr I Brown for measurements of plasma 25-hydroxyvitamin D, Mrs S Garrett for secretarial help, and medical and nursing staff on the neonatal unit for clinical management of the babies.

\section{References}

1 Kulkarni P B, Hall R T, Rhodes P G, et al. Rickets in very low-birth-weight infants. J Pediatr 1980; 96: 249-52.

2 Callenbach J C, Sheehan M B, Abramson S J, Hall R T. Etiological factors in rickets of very low-birth-weight infants. J Pediatr 1981; 98: 800-5.

3 Geggel R L, Pereira G R, Spackman T J. Fractured ribs: unusual presentation of rickets in premature infants. J Pediatr 1978; 93: 680-2.

4 Glasgow J F T, Thomas P S. Rachitic respiratory distress in small preterm infants. Arch Dis Child 1977; 52: 268-74.

5 Von Sydow G. A study of the development of rickets in premature infants. Acta Paediatr Scand [Suppl] 1946; 33: Supplement 2, 1-22.

- Rowe J C, Wood D H, Rowe D W, Raisz L G. Nutritional hypophosphatemic rickets in a premature infant fed on breast milk. N Engl J Med 1979; 300: 293-6.

7 Bosley A R J, Verrier-Jones E R, Campbell M J. Aetiological factors in rickets of prematurity. Arch Dis Child 1980 ; 55: 683-6.

8 Hillman L S, Haddad J G. Perinatal vitamin D metabolism. II. Serial 25 hydroxyvitamin D concentrations in sera of term and premature infants. $J$ Pediatr 1975; 86: 928-35.

9 Wolf $H$, Gräff V, Offerman $G$. Influence of vitamin $D_{3}$ on calcium metabolism in the newborn infant. In:
Norman $\mathrm{A}^{*} \mathrm{~W}$, S Schaefer K, Coburn J W, et al., eds. Vitamin $D$ basic research and its clinical applications. Berlin: De Gruyter, 1979: 866-8.

10 Seino Y, Ishii T, Shimotsuji T, Ishida M, Yabuuchi H. Plasma active vitamin $D$ concentrations in low-birthweight infants with rickets and its response to vitamin D treatment. Arch Dis Child 1981; 56: 628-32.

11 Glasgow J F T, Reid M. Letter: 1 ahydroxy vitamin D in nutritional rickets. Lancet 1977 ; ii: 302.

12 Technicon. Method AA II 03.

13 Technicon. Method AA II 04.

14 Technicon. Method AA II 6.

15 Haddad J G, Chyu K S. Competitive protein binding radioimmunoassay for 25 hydroxy cholecalciferol. $J$ Clin Endocrinol 1971; 33: 992-5.

16 Steichen J J, Tsang R C, Greer F R, Ho M, Hug G. Elevated serum 1, 25 dihydroxyvitamin $D$ concentrations in rickets of very low-birth-weight infants. $J$ Pediatr 1981 99: 293-8.

17 Chesney R W, Hamstra A J, De Luca H F. Rickets of prematurity. AmJ Dis Child 1981 ; 135: 34-7.

18 Chudley A E, Brown D R, Holzman I R, Oh K S Nutritional rickets in 2 very low-birth-weight infants with chronic lung disease. Arch Dis Child 1980; 55: 687-90.

19 Kovar I, Mayne P, Barltrop D. Plasma alkaline phosphatase activity: a screening test for rickets in preterm neonates. Lancet 1982; i : 308-10.

Correspondence to Dr N McIntosh, Department of Child Health, St George's Hospital Medical School, Cranmer Terrace, London SW17 ORE.

Received 2 July 1982 